\title{
Simultaneous determination of sulfonamides, tetracyclines and tiamulin in swine wastewater by solid-phase extraction and liquid chromatography-mass spectrometry
}

\author{
Weiwei Ben ${ }^{\mathrm{a}}$, Zhimin Qiang ${ }^{\mathrm{a}, *}$, Craig Adams ${ }^{\mathrm{b}}$, Heqing Zhang ${ }^{\mathrm{a}}$, Liping Chen $^{\mathrm{c}}$ \\ ${ }^{a}$ Research Center for Eco-Environmental Sciences, Chinese Academy of Sciences, 18 Shuang-qing Road, Hai-dian District, Beijing 100085, China \\ ${ }^{\mathrm{b}}$ Department of Civil, Environmental, and Architectural Engineering, University of Kansas, Lawrence, KS 66045, USA \\ c Environmental Protection Research Institute of Light Industry, Beijing 100089, China
}

\section{A R T I C L E I N F O}

\section{Article history:}

Received 22 April 2008

Received in revised form 28 June 2008

Accepted 8 July 2008

Available online 11 July 2008

\section{Keywords:}

Mass spectrometry

Antibiotics

Swine wastewater

Sulfonamide

Tetracycline

Macrolide

\begin{abstract}
A B S T R A C T
Little is known about the contamination level of antibiotics in swine wastewater in China. The highly complex matrix of swine wastewater, which generally has a chemical oxygen demand (COD) concentration as high as $15,000 \mathrm{mg} / \mathrm{L}$, makes it difficult to detect antibiotics at trace levels. In this work, a highly selective and sensitive analytical method was developed for simultaneous determination of three classes of commonly used veterinary antibiotics including five sulfonamides, three tetracyclines and one macrolide in swine wastewater using solid-phase extraction (SPE) and liquid chromatography-mass spectrometry (LC-MS). The method detection limits (MDL) in the swine wastewater were determined to be between 5 and $91 \mathrm{ng} / \mathrm{L}$, depending on specific antibiotics. Except sulfamethizole, all the other eight antibiotics were detected in the swine wastewaters collected from three concentrated swine feeding plants located in the Beijing (China) area, showing a concentration range of $0.62-32.67 \mu \mathrm{g} / \mathrm{L}$. These results reveal the representative concentration levels of selected antibiotics in the swine wastewaters of Beijing area.
\end{abstract}

(c) 2008 Elsevier B.V. All rights reserved.

\section{Introduction}

The occurrence of antibiotics in the environment has gained great attention around the globe in recent years because antibiotics can cause a genetic selection of resistant bacteria. Antibiotics are commonly used in concentrated animal feeding operations (CAFOs) worldwide to treat animal diseases and promote animal growth. However, the majority of applied antibiotics are excreted in feces and urine without metabolization in the gut of animals. Sulfonamides and tetracyclines are two classes of antibiotics broadly used in the CAFOs [1,2]. In recent years, tiamulin (a macrolide) has been widely applied in China for prophylaxis of dysentery and pneumonia, especially in pigs and poultry. The total active sulfonamide concentration in the mixed cattle and swine manure slurry was reported to be $20 \mathrm{mg} / \mathrm{kg}$ in Switzerland, and the tiamulin concentration was detected as $43 \mu \mathrm{g} / \mathrm{kg}$ in swine manure samples in Germany [3,4]. Relatively high levels of multiple classes of antibiotics were found in swine-manure storage lagoon wastewaters in the United States with total concentrations approaching $1 \mathrm{mg} / \mathrm{L}$ [5]. Eight sulfonamides were detected in swine wastewaters

\footnotetext{
* Corresponding author. Tel.: +8610 62849632; fax: +86 1062923541

E-mail address: qiangz@rcees.ac.cn (Z. Qiang).
}

in Malaysia with concentrations ranging from 5.1 to $95 \mathrm{ng} / \mathrm{L}$ [6]. It was reported that several classes of antibiotics (e.g., sulfonamides) are stable in the environment because they are resistant to biodegradation [7]. The application of manure to agricultural farmlands as fertilizer may cause the transmission of antibiotics and antibiotic resistant genes to soils and surrounding streams $[1,8,9]$. The United States Geological Survey (USGS) reported the occurrence of 21 antibiotic compounds in 139 streams all around the United States in a national reconnaissance conducted during 1999-2000, including tetracyclines, sulfonamides, macrolides and tylosin [10].

In China, over $8000 \mathrm{t}$ of antibiotics are used as feed additives each year (http://www.china-ah.com/baokan/hnxmsy/ show.php?id=5207, in Chinese). The abuse of antibiotics in the animal feeding industry is receiving serious concern. However, there is no regulation on antibiotics used as feed additives for promoting animal growth at present. To date, little is known about the concentration levels of antibiotics in the CAFO lagoons in China.

A number of analytical methods have been developed for detection of antibiotics in complex environmental matrices such as livestock tissues, milk, honey, soils and other matrices [11-13]. Yang et al. developed an analytical method for simultaneous detection of 11 tetracyclines and sulfonamides in the influent and effluent of domestic wastewater [14]. In recent years, quite a 
Table 1

Major physical-chemical properties of the selected antibiotics

\begin{tabular}{|c|c|c|c|}
\hline Antibiotics & MW & Structure & $\mathrm{p} K_{\mathrm{a}}^{\mathrm{a}}$ \\
\hline Sulfamethoxazole (SMX) & 253.3 & & $1.85 \pm 0.30,5.60 \pm 0.04$ \\
\hline Sulfathiazole (STZ) & 255.3 & & $2.01 \pm 0.30,7.11 \pm 0.09$ \\
\hline Sulfamethizole (SML) & 270.3 & & $1.86 \pm 0.30,5.29 \pm 0.04$ \\
\hline Sulfamethazine (SMN) & 278.3 & & $2.07 \pm 0.30,7.49 \pm 0.13$ \\
\hline Sulfadimethoxine (SDM) & 310.3 & & $2.13 \pm 0.30,6.08 \pm 0.09$ \\
\hline Tetracycline (TCN) & 444.4 & & $3.32 \pm 0.30,7.78 \pm 0.05$ \\
\hline Oxytetracycline (OTC) & 460.4 & & $3.22 \pm 0.30,7.46 \pm 0.03$ \\
\hline Chlortetracycline (CTC) & 478.9 & & $3.33 \pm 0.30,7.55 \pm 0.02$ \\
\hline Tiamulin (TIA) & 493.7 & & $7.6^{\mathrm{b}}$ \\
\hline
\end{tabular}

a From Ref. [21] (except tiamulin).

b http://www.tiamutin.com/vet-pig/respiratory/app/en/microbio.shtml.

few analytical methods for detection of veterinary antibiotics in swine wastewater and manure have been reported $[3,4,6,15,16,17]$. Because the organic components of swine wastewaters may differ greatly from one country to another due to different feeding styles, none of these reported methods was applicable to the swine wastewater samples taken from the CAFO sites in Beijing area during our preliminary tests. Additionally, no analytical method has been reported that is able to simultaneously separate and detect sulfonamides, tetracyclines, and tiamulin in swine wastewater with a highly complex matrix. Therefore, sensitive and reliable 
analytical methods are urgently needed to determine the contamination levels of veterinary antibiotics in CAFO lagoons in China.

Antibiotics generally appear at trace levels in the environment, so solid-phase extraction (SPE) procedures are commonly adopted to pre-concentrate and extract antibiotics from aqueous matrices. Hydrophilic-lipophilic balance (HLB) cartridges show good retention and recovery ratios for both polar and non-polar compounds, so they are generally applied to analyze antibiotics in environmental matrices instead of traditional sorbents such as C8, C18 and ion-exchange cartridges. For the purpose of mitigating the strong interference of matrices, tandem SPE methods were developed by combining strong anion exchange cartridges and HLB cartridges to clean up the natural organic matter (NOM) $[18,19]$. In particular, the SPE procedures for extracting antibiotics from complex matrices (e.g., milk) make great efforts on the cleaning steps to remove background interfering compounds as much as possible [20]. Similarly, the key point for the determination of antibiotics in swine wastewater is to develop highly efficient cleanup procedures for removal of interfering organics while retaining most of the antibiotics.

Because of their high sensitivity and selectivity, LC-MS and LC-MS-MS were generally used for antibiotics detection in environmental matrices. Though tandem MS is a powerful technique which can monitor a selected product ion formed from the collision-induced dissociation of a precursor ion [21], only a small portion of environmental laboratories can afford it, particularly in developing countries. The single MS still plays an important role in determining trace compounds.

This work was to develop an analytical method for simultaneous determination of nine antibiotics in swine wastewater with a chemical oxygen demand (COD) concentration as high as $15000 \mathrm{mg} / \mathrm{L}$ using SPE and LC-MS. The selected antibiotics are commonly used in Chinese CAFOs, including five sulfonamides, three tetracyclines and tiamulin. Table 1 shows the chemical structures and major physico-chemical properties of these antibiotics [22]. The linearity of calibration curve, recovery and precision, and method detection limit (MDL) were all assessed to ensure the applicability of the developed method. Thereafter, this method was applied to determine the concentration levels of selected antibiotics in swine wastewaters taken from three CAFO sites located in Beijing area.

\section{Experimental}

\subsection{Chemicals}

The studied antibiotics were purchased from the following sources: sulfathiazole (STZ, 99\%), sulfamethoxazole (SMX), sulfamethizole (SML), sulfadimethoxine (SDM), tetracycline hydrochloride (TCN, 95\%) and oxytetracycline hydrochloride (OTC, 95\%) from Sigma-Aldrich (St. Louis, MO, USA); sulfamethazine (SMN, 99\%) and chlortetracycline hydrochloride (CTC, 90\%) from Acros (New Jersey, USA); tiamulin fumarate (TIA, 98\%) from Dr. Ehrenstorfer (Augsburg, Germany). Acetonitrile and methanol (HPLC grade) were obtained from Fisher Scientific (Houston, TX, USA), and dichloromethane (ultra resi-analyzed grade) from J.T. Baker (Deventer, The Netherlands). Analytical grade formic acid, disodium ethylenediamine tetraacetate ( $\left.\mathrm{Na}_{2} \mathrm{EDTA}\right)$, acetone and other chemicals were all purchased from Beijing Chemical Reagents Company (Beijing, China).

The stock solutions of antibiotics were prepared by dissolving each compound in methanol at a concentration of $100 \mathrm{mg} / \mathrm{L}$. They were stored in refrigerator until use (sulfonamides and tiamulin at $4^{\circ} \mathrm{C}$, and tetracyclines at $-18^{\circ} \mathrm{C}$ ).
Table 2

Characteristics of swine wastewater used as the reference matrix collected from the anaerobic lagoon of a swine feeding plant in Changping District, Beijing (sampling date: 24 September 2007)

\begin{tabular}{lc}
\hline $\mathrm{pH}$ & 8.0 \\
$\mathrm{COD}(\mathrm{mg} / \mathrm{L})$ & 15,900 \\
$\mathrm{SCOD}(\mathrm{mg} / \mathrm{L})$ & 12,560 \\
$\mathrm{DOC}(\mathrm{mg} / \mathrm{L})$ & 3,325 \\
$\mathrm{TN}(\mathrm{mg} / \mathrm{L})$ & 780 \\
$\mathrm{NH}_{3}-\mathrm{N}(\mathrm{mg} / \mathrm{L})$ & 688 \\
$\mathrm{TP}(\mathrm{mg} / \mathrm{L})$ & 280 \\
Total alkalinity $(\mathrm{mg} / \mathrm{L})$ & 4,512 \\
$\mathrm{SS}(\mathrm{mg} / \mathrm{L})$ & 79 \\
\hline
\end{tabular}

COD, chemical oxygen demand; SCOD, soluble chemical oxygen demand; DOC, dissolved organic carbon; TN, total nitrogen; TP, total phosphorus.

\subsection{Sample collection and preparation}

The swine wastewater, which was used as reference matrix for method development, was collected from the anaerobic lagoon of a swine feeding plant located in Changping District, Beijing. The major chemical properties of the reference matrix are shown in Table 2. Chemical oxygen demand, soluble chemical oxidation demand (SCOD), free ammonia $\left(\mathrm{NH}_{3}-\mathrm{N}\right)$, total nitrogen (TN), total phosphorus (TP) were determined by Hach methods 8000, 10031, 10072, 10127 with a DR/5000 spectrophotometer (Hach Co., Loveland, USA), respectively. Suspended solids (SS) and total alkalinity were analyzed in accordance with the Standard Methods for the Examination of Water and Wastewater (APHA, 2005). The dissolved organic carbon (DOC) was obtained after filtering out SS with a Total Organic Carbon Analyzer (Phoenix 8000, Tekmar-Dohrmann Co., USA).

To restrain the activity of microorganisms, $1 \%$ methanol was added to swine wastewater sample immediately after sampling. The sample was centrifuged at $7000 \times g$ for 15 min by a centrifuge (Beckmann, J2-HS, USA) and the supernatant $\mathrm{pH}$ were adjusted with $\mathrm{H}_{2} \mathrm{SO}_{4}$ to 2.5-3.0. Then the supernatant were filtered through $0.45-\mu \mathrm{m}$ glass fiber filters and stored at $4{ }^{\circ} \mathrm{C}$ in a refrigerator until extraction within 2 days.

\subsection{Solid-phase extraction}

The COD of the reference matrix was as high as $15,900 \mathrm{mg} / \mathrm{L}$ which indicated the complexity of the matrix. However, antibiotics are usually present at trace levels in the swine wastewater $[1,6,23,24]$. As a result, the matrix will significantly affect the quantification of antibiotics (e.g., suppress the ionization of antibiotics in the ESI mode of LC-MS). In this work, SPE was applied to pre-concentrate the nine antibiotics and remove the background interfering compounds. The SPE procedures were carried out as

\section{Table 3}

Ion characteristics, retention times and optimal cone voltages of the selected antibiotics in the SIR mode

\begin{tabular}{lllll}
\hline Antibiotics & $\begin{array}{l}\text { Precursor } \\
\text { ions }(\mathrm{m} / \mathrm{z})\end{array}$ & $\begin{array}{l}\text { Qualifier } \\
\text { ions }(\mathrm{m} / \mathrm{z})\end{array}$ & $\begin{array}{l}\text { Retention } \\
\text { time }^{\mathrm{a}}(\mathrm{min})\end{array}$ & Cone voltage $(\mathrm{V})$ \\
\hline SMX & 254 & 156 & 23.5 & 20 \\
STZ & 256 & 156 & 8.7 & 20 \\
SML & 271 & 156 & 19.0 & 20 \\
SMN & 279 & 204 & 15.4 & 30 \\
SDM & 311 & 156 & 26.4 & 30 \\
TCN & 445 & 427 & 12.3 & 20 \\
OTC & 461 & 443 & 11.0 & 20 \\
CTC & 479 & 462 & 21.3 & 20 \\
TIA & 494 & 192 & 24.7 & 30 \\
\hline
\end{tabular}

a Obtained from the LC-MS extracted-ion SIR chromatograms of selected antibiotics in the reference matrix. 
follows: (1) adjust the $\mathrm{pH}$ of swine wastewater sample $(200 \mathrm{~mL}$ each) to $2.5-3.0$ with $40 \% \mathrm{H}_{2} \mathrm{SO}_{4}$, and add $0.1 \mathrm{~g}$ of $\mathrm{Na}_{2}$ EDTA to the sample to complex potential interfering metals; (2) precondition an Oasis HLB cartridge ( $500 \mathrm{mg} / 6 \mathrm{~mL}$, Waters, Milliford, MA) with $5 \mathrm{~mL}$ of methanol, $5 \mathrm{~mL}$ of $0.5 \mathrm{M} \mathrm{HCl}$ and $5 \mathrm{~mL}$ of deionized (DI) water sequentially; (3) extract the sample with the HLB cartridge at a flow rate of approximately $0.5 \mathrm{~mL} / \mathrm{min}$, and wash the cartridge with $5 \mathrm{~mL}$ of $5 \%$ methanol aqueous solution and $5 \mathrm{~mL}$ of DI water; (4) elute the antibiotics with $10 \mathrm{~mL}$ of a dichloromethane/acetone mixture $(3: 2, v / v) ;(5)$ dry the extract under a gentle stream of $\mathrm{N}_{2}$; (6) dissolve the dried residue with $0.8 \mathrm{~mL}$ of methanol and dilute with $1.2 \mathrm{~mL}$ of DI water. The final solution was analyzed with LC-MS.

\subsection{LC-MS system}

The LC system was Alliance Liquid Chromatography 2695 (Waters, USA). A Waters Symmetry C18 column $(2.1 \mathrm{~mm} \times 150 \mathrm{~mm}$, $5-\mu \mathrm{m}$ pore size) was used for separation of antibiotics in combination with a guard column $(2.1 \mathrm{~mm} \times 10 \mathrm{~mm})$. The injection volume was $20 \mu \mathrm{L}$ and column temperature was $30^{\circ} \mathrm{C}$. A combination of three mobile phases was used with a constant flow rate of $0.2 \mathrm{~mL} / \mathrm{min}$. Mobile phase A was composed of $99.8 \%$ water and $0.2 \%$ formic acid (v/v). Mobile phase B and $C$ were methanol and acetonitrile, respectively. The separation of antibiotics was achieved with a gradient program described as follows: the mobile phase ratio of $A: B: C$ was $90: 4: 6$ at 0 min and maintained for $10 \mathrm{~min}, 90: 0: 10$ at $11 \mathrm{~min}, 87: 0: 13$ at $13 \mathrm{~min}, 78: 0: 22$ at $15 \mathrm{~min}, 55: 0: 45$ at $25 \mathrm{~min}$, 0:0:100 at $26 \mathrm{~min}$ and maintained for $5 \mathrm{~min}, 90: 4: 6$ at $33 \mathrm{~min}$ and maintained for $12 \mathrm{~min}$ for column equilibration. The mobile phase ratio was changed linearly for each ramp. All the nine investigated antibiotics could be eluted within $28 \mathrm{~min}$.

The MS system consisted of a single-quadruple mass spectrometer ZQ 4000 (Waters, USA) equipped with an electrospray ionization (ESI) source and operated in the positive ion mode. The standard solutions of antibiotics prepared in DI water were first injected to optimize the MS operation parameters. The optimal conditions for the MS system were determined as follows: capillary temperature $120^{\circ} \mathrm{C}$; desolvation temperature $300^{\circ} \mathrm{C}$; capillary voltage $3.5 \mathrm{kV}$, and desolvation gas flow $300 \mathrm{~L} / \mathrm{h}$. Selected ion recording (SIR) mode was chosen to quantify the antibiotics. Cone voltage was also optimized for each antibiotic to obtain a higher sensitivity (Table 3).

\subsection{Identification and quantification}

Under a single MS and ESI $(+)$ mode, antibiotics are primarily transformed to the protonated molecular ions (i.e., $[\mathrm{M}+\mathrm{H}]^{+}$) that were used as precursor ions to quantify the antibiotics. One qualifier ion was chosen for each antibiotic for confirmation purpose along with the retention time. Standard calibration curves and matrix-matched calibration curves were both established for quantification of antibiotics in the DI water and the reference matrix. The spiked concentration ranges of antibiotics were set according to the method sensitivity for each antibiotic.

\subsection{Method validation}

The MDL in the DI water $\left(\mathrm{MDL}_{\mathrm{DI}}\right)$ was determined according to the Standard Methods for the Examination of Water and Wastewater (APHA, 2005). The matrix effect for each antibiotic was evaluated by the ratio of the signal response of spiked postextracted reference matrix sample to that of spiked DI water sample. Thus, the MDL in the swine wastewater (MDLSW) could be readily calculated based on the MDL $L_{D I}$ and the matrix effect. The recovery and precision of the developed method were also assessed by spiking two concentration levels of antibiotics to the reference matrix, which will be discussed in detail later.

\section{Results and discussion}

\subsection{Optimization of SPE}

Swine wastewater is a highly complex mixture consisting of proteins, carbohydrates, fats as well as various inorganic species [25]. On account of the significant matrix influence in the swine wastewater and diverse chemical properties of the nine antibiotics, an effective and simultaneous extraction of all the antibiotics was difficult to achieve. The combinations of HLB cartridge and SAX (strong anion exchange) or silica cartridge were tested to remove the matrices, but that made the SPE procedures overly complex. Besides, the recoveries of STZ and TCN decreased from $115 \%$ and $72 \%$ using HLB alone to $65 \%$ and $53 \%$ using the combination of SAX and HLB. The SAX cartridge tended to retain the antibiotics, thus decreasing the recovery efficiency. We later found that the HLB cartridge alone could effectively extract the antibiotics from the reference matrix if the composition of the eluent was properly adjusted.

Three wastewater volumes (i.e., 200,500 , and $1000 \mathrm{~mL}$ ) were examined to determine the breakthrough volume of the HLB cartridge. It was found that if the wastewater sample volume exceeded $500 \mathrm{~mL}$, the HLB cartridge could get saturated as a result of high matrix retaining. Taking safety factor into account, $200 \mathrm{~mL}$ of wastewater sample was extracted for each HLB cartridge. The $\mathrm{pH}$ of wastewater sample critically affected the retaining efficiency of antibiotics in the HLB cartridge. In this work, the wastewater sample was adjusted to $\mathrm{pH} 2.5-3.0$ with $40 \% \mathrm{H}_{2} \mathrm{SO}_{4}$ before being loaded to the HLB cartridge. It was observed that the recoveries of sulfonamides decreased notably when the wastewater $\mathrm{pH}$ was below 2.5 . The first ionization constants $\left(\mathrm{p} K_{\mathrm{a}, 1}\right)$ of the studied antibiotics are approximately in the range of $1.80-2.15$ (see Table 1). At a low pH value (e.g., $\mathrm{pH}<2.5$ ), more sulfonamides are transformed to cations (through protonating the amine moiety) which tend to penetrate the HLB cartridge.

Heavy metals such as $\mathrm{Cr}, \mathrm{Cu}, \mathrm{Ni}, \mathrm{Zn}$ and $\mathrm{Pb}$ are commonly present in the swine wastewater. The concentrations of heavy metals were determined to range from 3 to $70 \mu \mathrm{g} / \mathrm{L}$ for $\mathrm{Cr}$, $\mathrm{Ni}$ and $\mathrm{Pb}$, and from 1000 to $2000 \mu \mathrm{g} / \mathrm{L}$ for $\mathrm{Cu}$ and $\mathrm{Zn}$ in the swine wastewaters sampled from several CAFO sites in Beijing area. To improve the extraction efficiency, $\mathrm{Na}_{2}$ EDTA was added to chelate heavy metals to prevent their competitive binding to the adsorbing sites of the HLB cartridge.

Methanol solutions with different concentrations (5\%,20\% and $40 \%$ ) were assessed for the washing step attempting to partially remove the interfering organics retained by the HLB cartridge prior to elution of the antibiotics. The results show that $40 \%$ methanol solution did not wash out the antibiotics from the cartridge for the spiked DI water samples, but notably decreased the recovery efficiencies of the antibiotics for the spiked wastewater samples. It implies that the antibiotics could partially conjugate with some organic compounds present in the matrix. As a result, a high-concentration methanol solution could wash out the antibiotic-matrix conjugates, leading to a notable loss of antibiotics. It was found that little antibiotic was removed from the HLB cartridge if $5 \%$ methanol was used as the washing solution.

Most of the published methods used pure methanol to elute antibiotics from the cartridge after the washing step in the SPE. However, our results show that pure methanol could elute the extracted antibiotics along with a significant amount of the retained interfering organics due to the strong polarity of methanol as well as the high complexity of the swine wastewater. The total-ion 

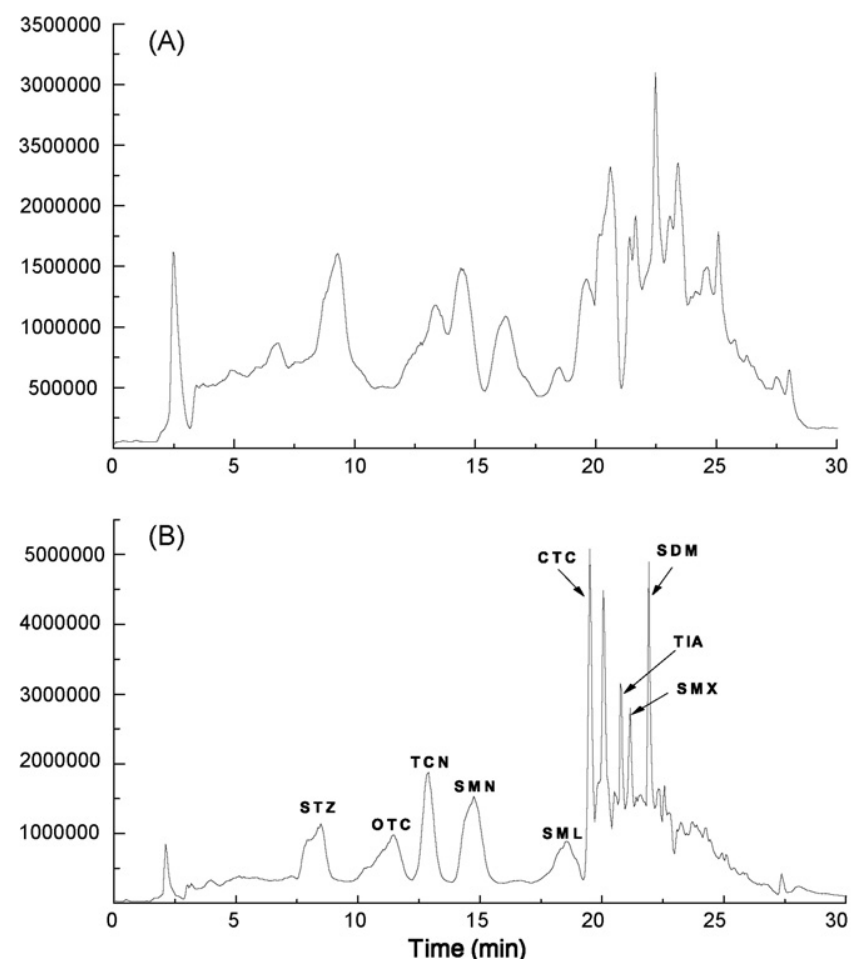

Fig. 1. Total-ion SIR chromatograms of the nine selected antibiotics obtained with different eluents: (A) methanol and (B) a dichloromethane/acetone mixture (3:2, $\mathrm{v} / \mathrm{v}$ ). The MS conditions are listed in Section 2.4. The LC conditions are described in Section 2.4 except that a different gradient program of the mobile phases was used. The gradient program was described as follows: the mobile phase ratio of $A: B: C$ was $90: 4: 6$ at $0 \mathrm{~min}$ and maintained for $10 \mathrm{~min}, 90: 0: 10$ at $11 \mathrm{~min}, 87: 0: 13$ at $13 \mathrm{~min}$, 60:0:40 at $15 \mathrm{~min}, 0: 0: 100$ at $22 \mathrm{~min}, 90: 4: 6$ at $25 \mathrm{~min}$ and maintained for $15 \mathrm{~min}$ for column equilibration. The mobile phase ratio was changed linearly for each ramp. The concentrations of antibiotics spiked in the swine wastewater samples were as follows: STZ, TCN, OTC, CTC $50 \mu \mathrm{g} / \mathrm{L}$; SMN, SML, SMX $20 \mu \mathrm{g} / \mathrm{L} ; \mathrm{SDM} 10 \mu \mathrm{g} / \mathrm{L}$; TIA $5 \mu \mathrm{g} / \mathrm{L}$.

SIR chromatograms, which were obtained by eluting antibiotics with methanol (Fig. 1A) and a dichloromethane/acetone mixture (Fig. 1B), clearly reflected that the peaks of antibiotics were severely covered by the matrix humps when pure methanol was used as eluent. In this work, several eluting solvents including cyclohexane, dichloromethane, ethyl acetate, acetone and methanol were tested individually or in combination to achieve a high extraction efficiency of the antibiotics while retaining the matrix organics in the HLB cartridge. The results show that a mixed eluent consisting of dichloromethane and acetone (3:2, v:v) could achieve the highest recovery of antibiotics and the least elution of matrix organics. After the elution procedure, the extract was dried under a gentle stream of nitrogen gas. Thereafter, $2 \mathrm{~mL}$ of methanol/DI water $(2: 3, v / v)$ was added in sequence to reconstitute the dried residue for LC-MS analysis. DI water was purposely added in this work to avoid peak distortion which had been commonly observed when only methanol was used to dissolve the residue [26].

\subsection{LC-MS method development}

The total-ion SIR chromatogram of nine antibiotics in the standard solutions is shown in Fig. 2. Owing to their diverse characteristics of the nine antibiotics especially polarity, various LC conditions had been tested to achieve a total separation of these antibiotics. Several mobile phase additives such as ammonium acetate, oxalic acid and acetic acid were used to obtain the highest sensitivity of most investigated antibiotics. Experimental results show that $0.2 \%$ formic acid was the most suitable additive to enhance the peak resolution and sensitivity. Most published methods preferred to use acetonitrile as the organic-solvent mobile phase for the analysis of sulfonamides and tetracyclines. In this work, a combination of three mobile phases was applied including methanol, acetonitrile, and DI water that contained $0.2 \%$ formic acid. Methanol was employed to adjust the total polarity of the mobile phases for adequate separation of STZ, OTC and TCN. A gradient program of the mobile phases, as previously described, was applied to improve the peak separation quality of antibiotics. After the gradient program was completed (i.e., at $26 \mathrm{~min}$ ), $100 \%$ acetonitrile was delivered to wash out highly retained compounds from the LC column (Symmetry C18) to prevent them from interfering with the subsequent analysis. Finally, the mobile phase ratio of $A: B: C$ was converted to the initial value (i.e., 90:4:6) and kept running for $12 \mathrm{~min}$ to re-equilibrate the column. Experimental results indicate that the temperature of LC column significantly impacted the mass peak quality of tetracyclines and the retention times of all antibiotics. The temperature of $30^{\circ} \mathrm{C}$ could yield a complete baseline separation for all the nine antibiotics, and moreover, a better mass peak symmetry for tetracyclines. Further increasing the column temperature would significantly shift the retention times of investigated antibiotics, leading to inefficient antibiotic separation, especially for TCN, OTC, SMX and TIA. In addition, the peak of CTC showed a quite severe tailing and distortion problem.

ESI (+) mode was chosen because of its high sensitivity to all kinds of antibiotics studied. The operational parameters affecting the ESI interface were optimized by flow injection analysis (FIA). The identification of individual antibiotics was based on the chromatographic retention time and two characteristic ions (see Table 3). The protonated adduct of the molecular ion, $[\mathrm{M}+\mathrm{H}]^{+}$, was used as the precursor ion for quantification of each antibiotic. Cone voltage was optimized for individual antibiotics to achieve the highest relative abundance of $[\mathrm{M}+\mathrm{H}]^{+}$among all the fragments. Every class of antibiotics exhibited characteristic fragmentation in the ESI $(+)$ mode. The fragment ion of $m / z 156$ that represents the sulfanilyl ring was selected as the qualifier ion for sulfonamides. Tetracyclines were discerned by their characteristic product ions in the form of $\left[\mathrm{M}+\mathrm{H}-\mathrm{H}_{2} \mathrm{O}\right]^{+}$. The fragment ion of $m / z$ 192, which results from the cleavage of the ester-bond, was selected as the qualifier ion for tiamulin. The LC-MS extracted-ion SIR chromatogram for the

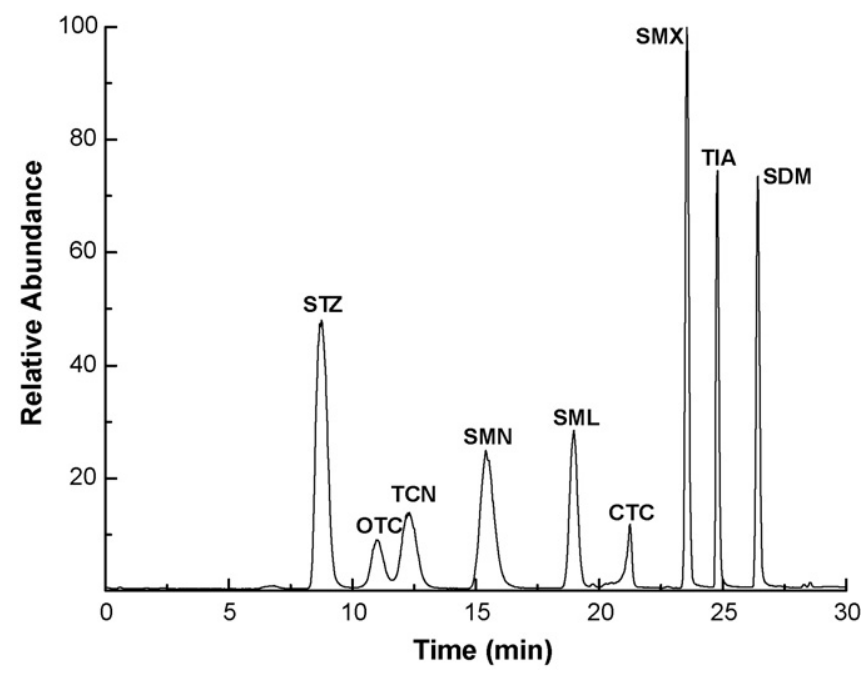

Fig. 2. Total-ion SIR chromatogram of the nine selected antibiotics prepared in DI water. The LC-MS conditions are listed in Section 2.4. The concentrations of antibiotics were as follows: STZ, TCN, OTC, CTC $5 \mathrm{mg} / \mathrm{L}$; SMN, SML, SMX $2 \mathrm{mg} / \mathrm{L} ; \mathrm{SDM}$ $1 \mathrm{mg} / \mathrm{L}$; TIA $0.5 \mathrm{mg} / \mathrm{L}$ 


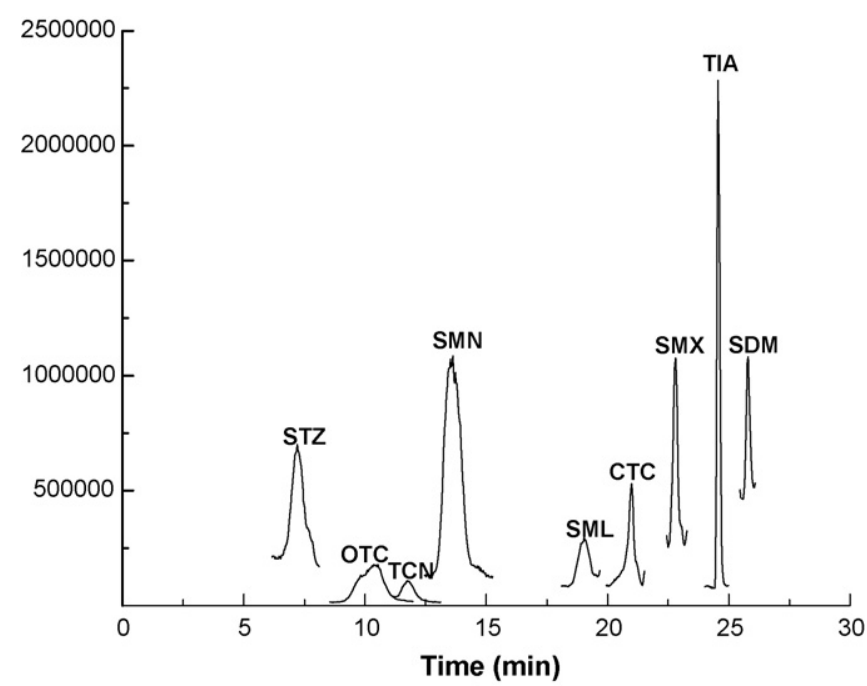

Fig. 3. Extracted-ion SIR chromatogram of the nine selected antibiotics prepared in reference matrix. The LC-MS conditions are listed in Section 2.4. The concentrations of antibiotics were as follows: SML $8 \mu \mathrm{g} / \mathrm{L}$; STZ, SMX, SMN, TCN, OTC, CTC $5 \mu \mathrm{g} / \mathrm{L}$; SDM $0.5 \mu \mathrm{g} / \mathrm{L}$; TIA $0.125 \mu \mathrm{g} / \mathrm{L}$.

nine antibiotics in reference matrix is shown in Fig. 3. It indicates that the developed method was highly selective for the investigated antibiotics.

\subsection{Calibration curves and linearity}

Because sample matrix tends to affect (either reduce or enhance) the ion intensities of target analytes, several published methods recommended use of matrix-matched calibration curves to determine the antibiotic concentrations [19,27,28]. The standard solutions of five sulfonamides, three tetracyclines and one macrolide (TIA) with a variety of concentrations, which were prepared in both DI water and the reference matrix as a mix, were used to establish the standard calibration curves and the matrixmatched calibration curves, respectively. The DI samples were directly analyzed to optimize the parameters of the LC-MS without SPE, thereafter the swine wastewater samples were analyzed with SPE under the optimized instrumental conditions. Since the concentrations of antibiotics are usually at $\mu \mathrm{g} / \mathrm{L}$ levels in swine wastewaters, the matrix-matched calibration curves were established in a much lower concentration range of antibiotics than that of the standard calibration curves. The linear regression data are summarized in Table 4, of which the coefficients of determination $\left(r^{2}\right)$ were all close to or greater than 0.99 for both the standard and matrix-matched calibration curves. The results indicate that the matrix-matched calibration curves could be well applied to quantify the nine antibiotics in the swine wastewater. For swine wastewaters from different sources, new matrix-matched calibration curves were established for accurate quantification of antibiotics.

\subsection{Recovery and precision}

Triplicate analyses were performed to determine the inward concentrations (i.e., the background concentrations) of investigated antibiotics in reference matrix samples. According to the Environmental Water Quality Monitoring Assurance Handbook (China National Environmental Monitoring Center, CNEMC), the recovery efficiency was determined by spiking one to three times the inward concentration of a target compound into the sample. The selected antibiotics with two concentration levels were spiked into the DI water and reference matrix samples which were afterwards treated through the whole developed procedures including SPE (extraction, washing, and elution) and LC-MS analysis. To determine the recoveries in the reference matrix, the inward concentrations of antibiotics were subtracted from the total concentrations determined by the matrix-matched calibration curves. Therefore, the antibiotics already present in the reference matrix would not interfere with the determination of recoveries. The recoveries of the nine antibiotics are summarized in Table 5, which ranged from $70 \%$ to $120 \%$ for both DI water samples (except SDM spiked at $0.5 \mu \mathrm{g} / \mathrm{L}$ that exhibited a recovery efficiency of $137 \%$ ) and the reference matrix samples. These recoveries were comparable to those of published methods for detection of antibiotics in wastewaters with a relatively simpler matrix (e.g., urine and sewage wastewater) [29,30].

The recovery precision expressed by the relative standard deviation (RSD, \%) was determined to be within the range of $0.9-13.7 \%$ for all the investigated antibiotics in both DI water and reference matrix samples. U.S. EPA recommends that a method be considered precise when the RSD is less than or equal to $20 \%$. For most of the antibiotics, their RSD values in the reference matrix samples were quite similar to those in the DI water samples.

\subsection{Matrix effect and method detection limit}

The MDL $\mathrm{DI}_{\mathrm{I}}$ was determined by analyzing seven spiked DI water samples at an antibiotic concentration level that provided signals at three times the background noises. The MDL $\mathrm{DI}_{\mathrm{D}}$ values of the investigated antibiotics are shown in Table 5. The results indicate that TIA had the lowest $\mathrm{MDL}_{\mathrm{DI}}(0.5 \mathrm{ng} / \mathrm{L})$, while OTC had the highest $\mathrm{MDL}_{\mathrm{DI}}(85 \mathrm{ng} / \mathrm{L})$. It is clearly seen that the sensitivity of the developed method towards antibiotics decreased with the order of TIA, sulfonamides, and tetracyclines.

Some investigated antibiotics were usually present at a relatively high inward concentration in the reference matrix, and it was almost impossible to find a swine wastewater that did not contain any of the investigated antibiotics. As a result, the MDLsw could not be directly determined in the same measure as $\mathrm{MDL}_{\mathrm{DI}}$. Instead, it

Table 4

Linear regression parameters of the selected antibiotics in DI water and reference matrix (each calibration curve includes five points)

\begin{tabular}{|c|c|c|c|c|c|c|c|c|}
\hline \multirow[t]{2}{*}{ Antibiotics } & \multicolumn{4}{|c|}{ Standard calibration curves (without SPE) } & \multicolumn{4}{|c|}{ Matrix-matched calibration curves (with SPE) } \\
\hline & Linearity range $(\mu \mathrm{g} / \mathrm{L})$ & Slope & $y$-intercept & $r^{2}$ & Linearity range $(\mu \mathrm{g} / \mathrm{L})$ & Slope & $y$-intercept & $r^{2}$ \\
\hline SMX & $2-200$ & 442,591 & -120 & 0.9997 & $0.5-25$ & 23,767 & $-16,933$ & 0.9998 \\
\hline $\mathrm{STZ}$ & $5-500$ & 173,786 & -203 & 0.9998 & $0.5-25$ & 19,381 & $-4,291$ & 0.9988 \\
\hline SML & $4-400$ & 256,637 & 1856 & 0.9996 & $0.5-25$ & 17,097 & $-35,871$ & 0.9994 \\
\hline SMN & $2-200$ & 523,600 & -58 & 0.9999 & $0.5-25$ & 47,631 & 399,805 & 0.9996 \\
\hline SDM & $1-100$ & $1,000,000$ & 57 & 0.9999 & $0.5-25$ & 71,292 & 31,098 & 0.9995 \\
\hline TCN & $10-1000$ & 134,219 & 169 & 0.9995 & $0.5-25$ & 8,518 & 5,399 & 0.9954 \\
\hline OTC & $10-1000$ & 85,756 & 940 & 0.9995 & $0.5-25$ & 3,266 & 31,240 & 0.9876 \\
\hline CTC & $10-1000$ & 134,497 & -939 & 0.9990 & $0.5-25$ & 2,618 & 4,938 & 0.9993 \\
\hline TIA & $1-100$ & $3,000,000$ & 5248 & 0.9989 & $0.5-25$ & 57,084 & 140,590 & 0.999 \\
\hline
\end{tabular}


Table 5

Recoveries, percent matrix effects and method detection limits (MDL) for the selected antibiotics in DI water and reference matrix, respectively

\begin{tabular}{|c|c|c|c|c|c|c|}
\hline \multirow[t]{2}{*}{ Antibiotics } & \multirow[t]{2}{*}{ Spike concentration $(\mu \mathrm{g} / \mathrm{L})$} & \multicolumn{2}{|c|}{ Recovery \pm RSD $(\%)^{\mathrm{a}}$} & \multirow[t]{2}{*}{$\% \mathrm{ME}^{\mathrm{b}}$} & \multirow[t]{2}{*}{$\mathrm{MDL}_{\mathrm{DI}}(\mathrm{ng} / \mathrm{L})$} & \multirow[t]{2}{*}{$\mathrm{MDL}_{\mathrm{SW}}(\mathrm{ng} / \mathrm{L})$} \\
\hline & & $\mathrm{DI}$ & $\mathrm{SW}^{\mathrm{c}}$ & & & \\
\hline SMX & $\begin{array}{l}1.0 \\
2.0\end{array}$ & $\begin{array}{l}93.8 \pm 9.8 \\
96.0 \pm 8.5\end{array}$ & $\begin{array}{l}112.5 \pm 6.1 \\
121.7 \pm 1.7\end{array}$ & 31 & 6.4 & 21 \\
\hline STZ & $\begin{array}{l}2.0 \\
5.0\end{array}$ & $\begin{array}{r}91.1 \pm 6.8 \\
70.0 \pm 4.9\end{array}$ & $\begin{array}{l}78.9 \pm 7.3 \\
76.0 \pm 3.3\end{array}$ & 130 & 20 & 15 \\
\hline SML & $\begin{array}{l}1.0 \\
2.0\end{array}$ & $\begin{array}{l}79.7 \pm 13.7 \\
91.7 \pm 8.3\end{array}$ & $\begin{aligned} 113.7 & \pm 10.6 \\
98.7 & \pm 4.2\end{aligned}$ & 68 & 6 & 9 \\
\hline SMN & $\begin{array}{l}10.0 \\
20.0\end{array}$ & $\begin{array}{l}91.0 \pm 8.6 \\
96.2 \pm 12.5\end{array}$ & $\begin{array}{l}104.7 \pm 3.1 \\
100.6 \pm 3.6\end{array}$ & 103 & 18 & 18 \\
\hline SDM & $\begin{array}{l}0.5 \\
1.0\end{array}$ & $\begin{array}{r}137.0 \pm 6.1 \\
100.0 \pm 7.0\end{array}$ & $\begin{array}{r}100.0 \pm 2.0 \\
95.0 \pm 5.8\end{array}$ & 33 & 3 & 10 \\
\hline TCN & $\begin{array}{l}1.0 \\
2.0\end{array}$ & $\begin{array}{l}88.3 \pm 0.9 \\
98.2 \pm 5.6\end{array}$ & $\begin{array}{l}101.8 \pm 2.6 \\
113.5 \pm 6.9\end{array}$ & 88 & 40 & 45 \\
\hline OTC & $\begin{array}{l}10.0 \\
20.0\end{array}$ & $\begin{array}{r}106.0 \pm 3.3 \\
99.3 \pm 0.2\end{array}$ & $\begin{array}{c}89.7 \pm 5.6 \\
102.3 \pm 11.1\end{array}$ & 93 & 85 & 91 \\
\hline CTC & $\begin{array}{l}2.5 \\
5.0\end{array}$ & $\begin{array}{r}104.3 \pm 9.2 \\
96.1 \pm 7.8\end{array}$ & $\begin{array}{r}95.3 \pm 5.8 \\
101.0 \pm 5.2\end{array}$ & 62 & 38 & 61 \\
\hline TIA & $\begin{array}{l}2.5 \\
5.0\end{array}$ & $\begin{array}{r}104.0 \pm 3.8 \\
94.0 \pm 2.8\end{array}$ & $\begin{array}{l}99.0 \pm 3.6 \\
99.3 \pm 2.3\end{array}$ & 38 & 0.5 & 1.32 \\
\hline
\end{tabular}

a Determined by triplicate analyses.

b ME: matrix effect.

c SW: swine wastewater used as reference matrix.

was calculated through dividing the $\mathrm{MDL}_{\mathrm{DI}}$ by the percent matrix effect (\%ME) for each antibiotic. The \%ME, which represents how the matrix may interfere with the analyte's signal, is calculated by the following equation [31]: the developed method, although based on single MS, still had a good applicability for detecting the selected antibiotics in swine wastewaters from the CAFO sites in Beijing area.

$$
\% \mathrm{ME}=\frac{\text { signal response of spiked post-extracted reference matrix sample }}{\text { signal response of spiked DI water sample }} \times 100
$$

It is seen that $100 \% \mathrm{ME}$ means no matrix interference with the analyte's signal. The values of \%ME for the investigated antibiotics are shown in Table 5. The results indicate that the effect of the reference matrix on the determination of antibiotics could be approximately classified into three levels, i.e., high interference with SMX, SDM and TIA (31-38\%); middle interference with STZ, SML and CTC (62-68\% and 130\%), low interference with SMN, TCN and OTC (88-103\%). It appears that the matrix effect is not pertinent to the class of antibiotics, but specific to each antibiotic. Table 5 also shows that the MDL $\mathrm{SW}_{\mathrm{SW}}$ for the nine antibiotics ranged from $1.32 \mathrm{ng} / \mathrm{L}$ (TIA) to $91 \mathrm{ng} / \mathrm{L}$ (OTC), which are comparable to the MDLs reported by other researchers based on tandem MS [14,21]. It is seen that

\section{Table 6}

Antibiotic concentrations detected in swine wastewaters collected from three CAFO sites in Beijing area

\begin{tabular}{llll}
\hline Antibiotics & \multicolumn{3}{l}{ Mean $\pm \mathrm{SD}^{\mathrm{a}}(\mu \mathrm{g} / \mathrm{L})$} \\
\cline { 2 - 4 } & Changping District & Haidian District $^{\mathrm{b}}$ & Shunyi District \\
\hline SMX & $1.01 \pm 0.03$ & $\mathrm{ND}$ & $\mathrm{ND}$ \\
STZ & $\mathrm{ND}^{\mathrm{c}}$ & $9.83 \pm 0.02$ & $\mathrm{ND}$ \\
SML & $\mathrm{ND}$ & $\mathrm{ND}$ & $\mathrm{ND}$ \\
SMN & $7.90 \pm 0.50$ & $10.07 \pm 0.67$ & $\mathrm{ND}$ \\
SDM & $0.62 \pm 0.01$ & $\mathrm{ND}$ & $14.05 \pm 0.08$ \\
TCN & $1.14 \pm 0.18$ & $4.62 \pm 0.26$ & $1.32 \pm 0.24$ \\
OTC & $10.48 \pm 0.58$ & $6.18 \pm 0.10$ & $25.36 \pm 1.01$ \\
CTC & $2.65 \pm 0.15$ & $32.67 \pm 1.59$ & $4.31 \pm 0.34$ \\
TIA & $2.14 \pm 0.02$ & $5.08 \pm 0.12$ & ND \\
\hline
\end{tabular}

a Determined by triplicate analyses.

b Sample was diluted by two times before analysis.

c ND: not detected.

\subsection{Concentrations of antibiotics in typical CAFOs in Beijing area}

To date, little is known about the concentration levels of antibiotics in the swine wastewaters in China. The developed method was thus applied to determine the concentrations of the investigated antibiotics in swine wastewaters collected from anaerobic lagoons of three concentrated swine feeding plants located in Changping, Haidian and Shunyi Districts of Beijing in June, October and January, respectively. Each plant had a yearly production of about 10,000 pigs. Triplicate analyses were performed for each wastewater to calculate the mean concentrations and standard deviations of the antibiotics.

Table 6 shows that except SML, all the other eight antibiotics were detected in different swine wastewaters with concentrations ranging from 0.62 to $32.67 \mu \mathrm{g} / \mathrm{L}$. Tetracyclines were detected in all the three swine wastewaters with relatively high concentrations (e.g., $25.36 \mu \mathrm{g} / \mathrm{L}$ OTC in the Shunyi wastewater and $32.67 \mu \mathrm{g} / \mathrm{L}$ CTC in the Haidian wastewater), implying that tetracyclines may be most commonly used in Beijing CAFOs. This agrees well with our survey information. Sulfonamides were detected at the least frequency, however. SML was not detected in any wastewater. SMX $(1.01 \mu \mathrm{g} / \mathrm{L})$ and STZ $(9.83 \mu \mathrm{g} / \mathrm{L})$ were only detected in one wastewater. SMN (7.90-10.07 $\mu \mathrm{g} / \mathrm{L})$ and SDM $(0.62-14.05 \mu \mathrm{g} / \mathrm{L})$ were detected in two wastewaters. TIA was found in two wastewaters with concentrations of 2.14 and $5.08 \mu \mathrm{g} / \mathrm{L}$. These data reveal the concentration levels of selected antibiotics in the swine wastewaters, and moreover, may indirectly sketch out the current application status of veterinary antibiotics in Beijing area. 


\section{Conclusions}

The purpose of this work was to develop a simultaneous detection method for quantification of nine selected antibiotics including five sulfonamides, three tetracyclines and one macrolide (TIA) in swine wastewater using SPE and LC-MS. Relatively simple but highly efficient SPE procedures were developed through optimizing the composition of the elution solvent for cleanup and enrichment of the antibiotics in the reference matrix (swine wastewater). The method was validated by the linearity of calibration curves, and the recovery, precision and MDL of each antibiotic studied. Thereafter, the method was applied to determine the concentration levels of selected antibiotics in swine wastewaters collected from three CAFO plants located in Beijing area. Except SML, all the other eight antibiotics were detected in the swine wastewaters with concentrations ranging from 0.62 to $32.67 \mu \mathrm{g} / \mathrm{L}$. Since the swine wastewater has a highly complex matrix which is reflected by its high COD concentration (about $15,000 \mathrm{mg} / \mathrm{L}$ ), this developed method may be readily extended to other types of relatively simpler matrices such as the influent and effluent of sewage treatment plants, urine, and surface waters.

This research has demonstrated the swine wastewater is an important pollution source of veterinary antibiotics. If applied to agricultural farms, the antibiotics in the swine wastewater might contaminate the soils and surrounding water bodies, thus posing a serious threat to human livings and wildlife $[1,8,9]$. Further research will be conducted to develop control and treatment measures to prevent the release of antibiotic from swine wastewaters to the environment.

\section{Acknowledgements}

We would like to thank Zhiyong Yu, Guangshu Zhai and other members in the public instrument group of the State Key Laboratory of Environmental Aquatic Chemistry for analytical support. This work was financially supported by the National High Technology R\&D (863) Program (project \# 2007AA06Z344) and the Funds for Creative Research Groups of China (project \# 50621804).

\section{References}

[1] A.K. Sarmah, M.T. Meyer, A.B.A. Boxall, Chemosphere 65 (2006) 725

[2] P. Sukul, M. Spiteller, Rev. Environ. Contam. Toxicol. 187 (2006) 67.

[3] M.Y. Haller, S.R. Müller, C.S. McArdell, A.C. Alder, M.J.-F. Suter, J. Chromatogr. A $952(2002) 111$.

[4] M.P. Schlüsener, K. Bester, M. Spiteller, Anal. Bioanal. Chem. 375 (2003) 942

[5] E.R. Campagnolo, K.R. Johnson, A. Karpati, C.S. Rubin, D.W. Kolpin, M.T. Meyer, J.E. Esteban, R.W. Currier, K. Smith, K.M. Thu, M. McGeehin, Sci. Total Environ. 299 (2002) 89.

[6] N.T. Malintan, M.A. Mohd, J. Chromatogr. A 1127 (2006) 154

[7] S. Kim, P. Eichhorn, J.N. Jensen, A.S. Weber, D.S. Aga, Environ. Sci. Technol. 39 (2005) 5816

[8] G. Hamscher, H.T. Pawelzick, H. Höper, H. Nau, Environ. Toxicol. Chem. 24(2005) 861.

[9] J. Tolls, Environ. Sci. Technol. 35 (2001) 3397.

[10] D.W. Kolpin, E.T. Furlong, M.T. Meyer, E.M. Thurman, S.D. Zaugg, L.B. Barber, H.T Buxton, Environ. Sci. Technol. 36 (2002) 1202.

[11] S. Bogialli, R. Curini, A.D. Corcia, A. Laganà, G. Rizzuti, J. Agr. Food Chem. 54 (2006) 1564

[12] M.E. Lindsey, M. Meyer, E.M. Thurman, Anal. Chem. 73 (2001) 4640.

[13] K.E. Maudens, G.-F. Zhang, W.E. Lambert, J. Chromatogr. A 1047 (2004) 85.

[14] S. Yang, J. Cha, K. Carlson, J. Chromatogr. A 1097 (2005) 40.

[15] A.M. Jacobsen, B. Halling-Sørensen, Anal. Bioanal. Chem. 384 (2006) 1164

[16] P.A. Blackwell, H.-C.H. Lützhøft, H.-P. Ma, B. Halling-Sørensen, A.B.A. Boxall, P. Kay, Talanta 64 (2004) 1058.

[17] M.P. Schlüsener, M.A. von Arb, K. Bester, Arch. Environ. Contam. Toxicol. 51 (2006) 21

[18] K.G. Karthikeyan, M.T. Meyer, Sci. Total Environ. 361 (2006) 196

[19] A.M. Jacobsen, B. Halling-Sørensen, F. Ingerslev, S.H. Hansen, J. Chromatogr. A 1038 (2004) 157

[20] U. Koesukwiwat, S. Jayanta, N. Leepipatpiboon, J. Chromatogr. A 1149 (2007) 102.

[21] J. Zhu, D.D. Snow, D.A. Cassada, S.J. Monson, R.F. Spalding, J. Chromatogr. A 982 (2001) 177.

[22] Z. Qiang, C. Adams, Water Res. 38 (2004) 2874.

[23] P. Eichhorn, D.S. Aga, Anal. Chem. 76 (2004) 6002.

[24] M.T. Meyer, J.E. Bumgarner, J.L. Varns, J.V. Daughtridge, E.M. Thurman, K.A Hostetler, Sci. Total Environ. 248 (2000) 181.

[25] K.A. Loftin, C. Henny, C.D. Adams, R. Surampali, M.R. Mormile, Environ. Toxicol. Chem. 24 (2005) 782.

[26] S. Reverté, F. Borrull, E. Pocurull, R.M. Marcé, J. Chromatogr. A 1010 (2003) 225

[27] U. Koesukwiwat, S. Jayanta, N. Leepipatpiboon, J. Chromatogr. A 1140 (2007) 147.

[28] M.J. Nozal, J.L. Bernal, M.T. Martín, J.J. Jiménez, J. Bernal, M. Higes, J. Chromatogr. A 1116 (2006) 102

[29] J. Tuerk, M. Reinders, D. Dreyer, T.K. Kiffmeyer, J. Chromatogr. B 831 (2006) 72.

[30] V. Koutsouba, Th. Heberer, B. Fuhrmann, K. Schmidt-Baumler, D. Tsipi, A. Hiskia Chemosphere 51 (2003) 69.

[31] B.K. Matuszewski, M.L. Constanzer, C.M. Chavez-Eng, Anal. Chem. 75 (2003) 3019. 